\title{
Climate Change Impacts on Water Resources and Reservoir Management: Uncertainty and Adaptation for a Mountain Catchment in Northeast Portugal
}

\author{
Claudia Carvalho-Santos ${ }^{1,2}$ (D) António T. Monteiro ${ }^{2} \cdot$ \\ João C. Azevedo ${ }^{3}$ • João Pradinho Honrado ${ }^{2,4}$. \\ João Pedro Nunes ${ }^{1,5}$
}

Received: 21 July 2016 / Accepted: 20 April 2017 /

Published online: 9 May 2017

(C) Springer Science+Business Media Dordrecht 2017

\begin{abstract}
Reservoirs often play an important role in mitigating water supply problems. However, the implications of climate change are not always considered in reservoir planning and management. This study aimed to address this challenge in the Alto Sabor watershed, northeast Portugal. The study analysed whether or not the shortage of water supply can be effectively addressed through the construction of a new reservoir (two-reservoir system) by considering future climate projections. The hydrological model Soil and Water Assessment Tool (SWAT) was calibrated and validated against daily-observed discharge and reservoir volume, with a good agreement between model predictions and observations. Outputs from four General Circulation Models (GCM) for two scenarios (RCP 4.5 and 8.5) were statistically downscaled and bias-corrected with ground observations. A general increase in temperature is expected in the future while the change in precipitation is more uncertain as per the differences among climatic models. In general, annual precipitation would slightly decrease while seasonal changes would be more significant, with more precipitation in winter and much less in spring and summer. SWAT simulations suggest that the existence of two-reservoir will better
\end{abstract}

Claudia Carvalho-Santos

c.carvalho.santos@cibio.up.pt; c.carvalho.santos@ua.pt

1 CESAM - Centro de Estudos do Ambiente e do Mar \& Dept. de Ambiente e Planeamento, Universidade de Aveiro, 3810-193 Aveiro, Portugal

2 CIBIO/InBio - Centro de Investigação em Biodiversidade e Recursos Genéticos, Universidade do Porto, Campus Agrário Vairão, Rua Padre Armando Quintas, n 7, 4485-661 Vila do Conde, Portugal

3 CIMO - Centro de Investigação de Montanha \& Departamento de Ambiente e Recursos Naturais, Instituto Politécnico de Bragança, 5300-253 Bragança, Portugal

4 Faculdade de Ciências, Universidade do Porto, Rua do Campo Alegre, FC4-Biologia, 4169-007 Porto, Portugal

5 CE3C - Centro de Ecologia, Evolução Alterações Climáticas, Faculdade de Ciências, Universidade de Lisboa, 1749-016 Lisboa, Portugal 
solve the water supply problems under current climate conditions compared to a singlereservoir system. However in the future, the reliability of this solution will decrease, especially due to the variability of projections from the different climatic models. The solution to water supply problems in this region, adopted taking only present-day climate into account, will likely be inefficient for water supply management under future climate conditions.

Keywords Alto Saborwatershed $\cdot$ Climate change $\cdot$ SWAT model $\cdot$ Reservoir management $\cdot$ RCP scenarios · Water supply

\section{Introduction}

There is evidence that climate is changing in the Mediterranean region of Europe, with warmer temperatures and a change in the intensity and pattern of precipitation predicted for the future (Giorgi and Lionello 2008; Feng et al. 2014). One of the main concerns related with future climate is the potential change in the availability of water resources, common to dry regions around the world such as the Mediterranean (Kundzewicz et al. 2008; Shen et al. 2010;). This is particularly important because water is a primary resource for household, hydropower production, industry and irrigation (Falkenmark and Rockstrom 2004). Therefore, ensuring water quantity, quality and seasonality is an important concern for policy makers and stakeholders under the European agenda (Tsakiris 2015). On the other hand, water scarcity is not only dependent on meteorological drought, that is, the lack of precipitation during a certain period, but also on non-meteorological factors, such as high water demands and lack of or inadequate water related infra-structures (e.g. reservoirs) (Martin-Carrasco and Garrote 2007; Iglesias et al. 2011).

In Portugal, future change in the pattern of precipitation is a very important issue, as it can aggravate the typical seasonality with dry, hot summers and wet winters. The main hydrological consequences for the basins in northern Portugal are a reduction of discharge in spring and summer, and an increase of runoff in winter (Cunha et al. 2002). From the demand side, Portugal is generally considered a low water stress country (abstractions are lower than $40 \%$ of available water) when compared to other Mediterranean countries such as Spain, Malta and Cyprus (EEA 2003). However, some regions in Portugal frequently suffer from water supply problems during summer, namely in the south and in the interior north (Cunha et al. 2002; Nunes et al. 2008; Mourato et al. 2015). Water management strategies, especially the construction of reservoirs for water storage, have significantly influenced the natural hydrological response to meteorological droughts thus minimizing the impacts of precipitation deficits (Lorenzo-Lacruz et al. 2013).

Many studies have shown the impact of climate change on natural hydrological regimes in the Mediterranean watersheds, but the impact on regulated systems is much less known. These studies are important to evaluate the reliability of current and future water supply, anticipating the consequences of prolonged precipitation deficits (Iglesias et al. 2011). In Spain, studies have shown that water level in reservoirs can be severely impacted by climate change, especially during summer (Bangash et al. 2013; Molina-Navarro et al. 2014; López-Moreno et al. 2014). In Sardinia, Italy, Mereu et al. (2016) described a reservoir with good resilience to future climate change. The resilience is mostly because of a large basin feeding it. The reservoir was only affected if associated with increasing water demand from the agricultural sector. The authors, however, argue that this may not be the case for other reservoirs in the region and that a detailed assessment is needed (Mereu et al. 2016). The resilience of 
vulnerable reservoirs must be studied and should take climate change into account, otherwise they might become inadequate in adverse climate conditions.

This study aimed to simulate the impacts of climate change on reservoir water supply in a mountain watershed of northeast Portugal (Alto Sabor) and to test if the water supply system will be reliable under climate change. This watershed suffers from water supply limitations during dry summers, coinciding with higher demand from increasing population. A new reservoir for water supply was built in the upper catchment and started filling in 2015, complementing an older reservoir in a neighbouring location. However, it is currently not known whether the system is prepared for the climate change impacts. Therefore, this study will answer the following three questions: (1) Is the two-reservoir system improving the current capacity of water supply? (2) Is the two-reservoir system better prepared for future climate conditions, compared to the single-reservoir condition? and finally (3) Will this solution be enough to ensure reliable water supply under future climate conditions?

\section{Methods and Data}

\subsection{Study Area}

Alto Sabor $\left(403 \mathrm{~km}^{2}\right)$, in northeast Portugal, corresponds to the upstream part of the Sabor river watershed; a quarter of the Alto Sabor area (the headwaters) is located in Spain (Fig. 1).

The climate is Mediterranean with three dry months in summer (June, July and August), but with transition to humid (Mesquita and Sousa 2009). Precipitation varies from about $700 \mathrm{~mm}$ annual averages in lowlands to $1100 \mathrm{~mm}$ upstream in the mountains. The mean annual discharge is about two thirds of precipitation.

The watershed is almost totally located in a mountainous area of the Montesinho Natural Park, a natural wooded and traditional mountain agricultural landscape, with high natural value (Castro et al. 2010). Regarding land cover, shrubland and forest areas occupy the highlands, whereas agriculture is common in lowlands (Fig. 1a). In the last two decades, the agricultural area for annual crops decreased, either by changing into permanent crops (chestnut production), or due to land abandonment with fields being occupied by shrubland. Currently, shrubland areas occupy about $52 \%$ of the watershed (Table 1 ).

Slopes are very steep (above $25 \%$ ) in $22 \%$ of the area, and steep (between 10 and $25 \%$ ) in $46 \%$ of the area.

The geology is granitic in the upper regions and schist in the lower areas. Soils are shallow, mainly umbric leptosols from granite or schist (70\%), and eutric leptosols (15\%); the rest of the area is covered by cambisols and luvisols (Fig. 1b).

Urban areas have been increasing since 1990, mainly in Bragança (the major city located in the south of the watershed). There is a small reservoir (Serra Serrada) and a new major reservoir (Veiguinhas) upstream in Montesinho mountain for the main purpose of domestic water supply (Fig. 1).

\subsection{SWAT Hydrological Model Setup}

SWAT is a physically based semi-distributed model with daily and monthly calculations of hydrological balance parameters in a watershed (Arnold et al. 1998; Neitsch et al. 2011). The Alto Sabor watershed was divided into homogeneous simulation 


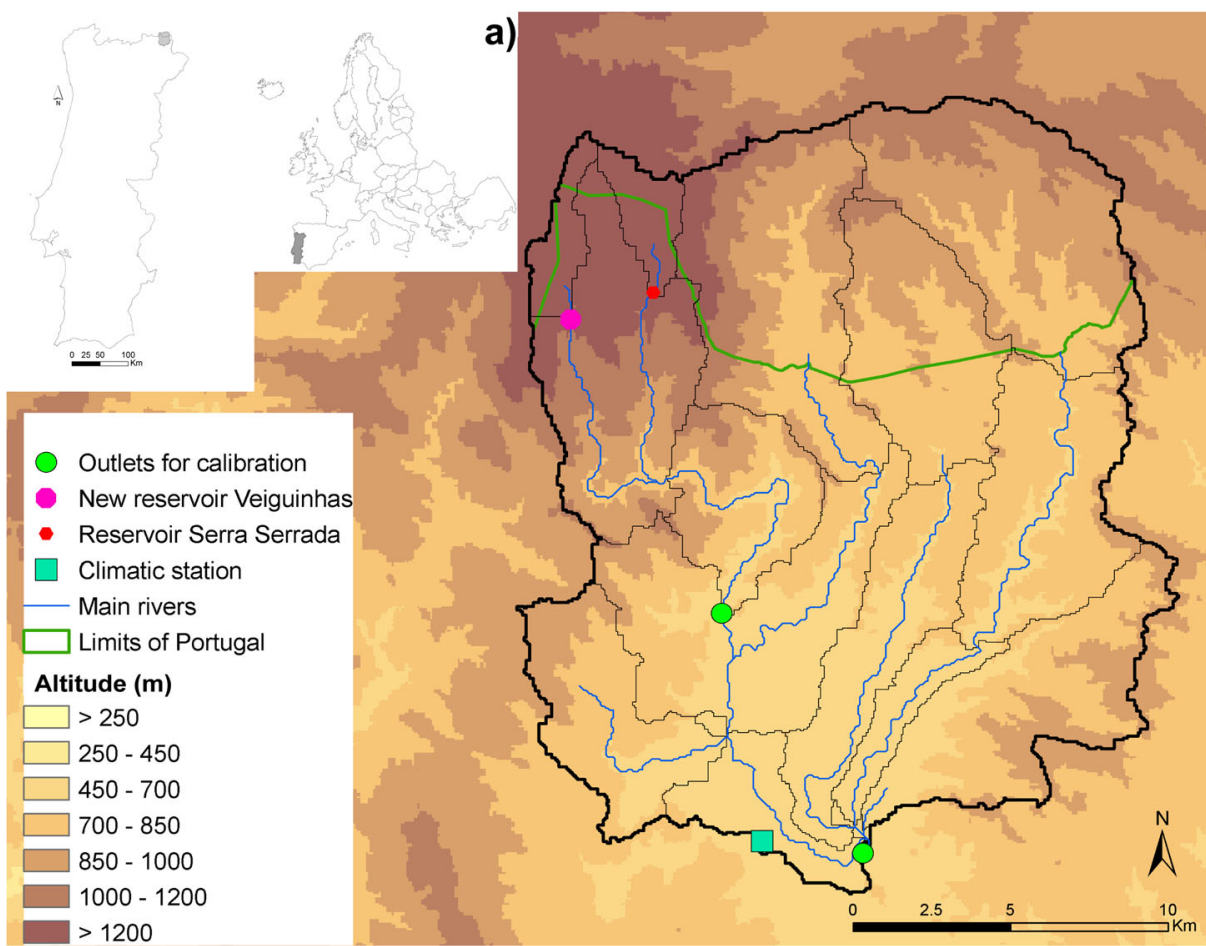

b)

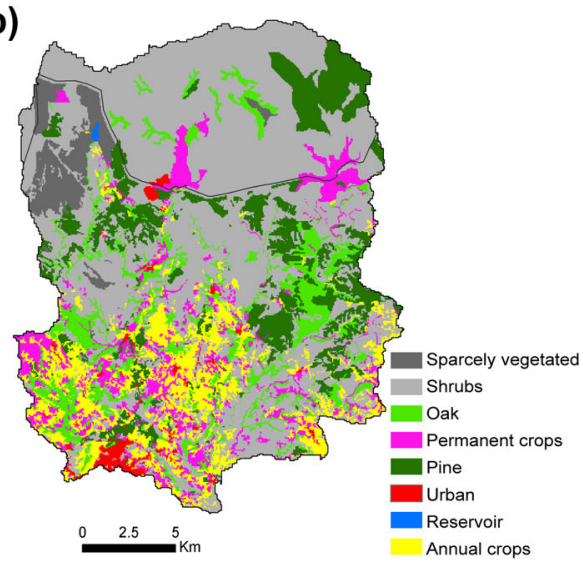

c)

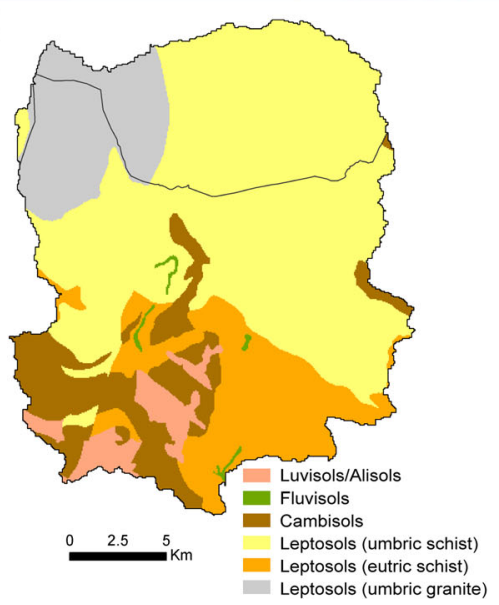

Fig. 1 a Location map of Alto Sabor watershed in northeast Portugal with 14 sub-basins (brown limits), and the altitude classes; b Land cover map 2007 (IGP 2007); c Soil map (Agroconsultores-COBA 1991)

units, the Hydrologic Response Units (HRUs). Each of the HRUs consists of a unique combination of land use, soil type, and slope features (Gassman et al. 2007). To predict surface runoff from precipitation or different types of soil and land cover, the curve number (CN) equation method was used in this simulation (Arnold et al. 1998). SWAT includes also routines allowing the simulation of vegetation growth from seedling to mature stands, considering plant phenological development, leaf area, radiation interception, and biomass (Gassman et al. 2007). 
Input datasets and data sources for SWAT calibration in the Alto Sabor watershed are presented in Table 2. Land cover classes of the original dataset were divided into seven major groups, representing the similarities in terms of hydrological properties (Table 1). The generic parameterization of vegetation was based on the previous SWAT application in the Vez watershed, northwest Portugal (Carvalho-Santos et al. 2016). Six major soil groups were used (Table 2). Both land cover and soil maps were aggregated with similar datasets for the Spanish part of the watershed and the same parameters were applied (the headwaters of Alto Sabor). Climate parameters (precipitation, maximum and minimum temperature, solar radiation, relative humidity and wind speed) were used from the Bragança weather station, located in the south of the watershed (Fig. 1). Four extra precipitation data series inside the basin were rejected because of large gaps. However, they were used to calculate a rate of precipitation change with altitude using several years with data for all stations between 1974 and 2007. To improve precipitation representation, a virtual station was created in the centroid of each of the fourteen sub-basins, in which daily precipitation measured at the Bragança weather station is multiplied by a topographic lapse ratio for each sub-basin (Galván et al. 2014). Solar radiation data (Srad) was available only for the period 1974-1984 (WRDC 2015). In the absence of solar radiation data for the simulation period, solar radiation was then estimated based on a modified Hargreaves-Samani equation ( $\mathrm{Srad}=\mathrm{KT} * \mathrm{Ho} *(\mathrm{TD})^{0.5}$ ) (Samani 2000), in which KT is an empirical coefficient, calculated from a linear regression between observed Srad data and other meteorological variables (wind speed, relative humidity and average temperature); Ho is the extra-terrestrial solar radiation, calculated based on astronomic equations and latitude; and TD is the difference of maximum and minimum daily temperature. The observed Srad data at Bragança weather station was useful to validate the estimation, resulting in $r^{2}=0.74$.

Model setup was done using the ArcSWAT 2009.93.7a interface for ArcGis (Winchell et al. 2010). A digital elevation model (DEM) was used for watershed discretization and delineation, resulting in 14 sub-basins. In this step a reservoir (Serra Serrada) was added to the simulation. Subsequently, slope, land cover and soil data (Table 2) were applied for model parameterization, resulting in $660 \mathrm{HRUs}$. Slope was divided into 3 classes, defined in order to represent the heterogeneity of this variable in the watershed: $0-10 \% ; 10-25 \% ;>25 \%$. The land cover class permanent crop was divided into $85 \%$ traditional orchard and $25 \%$ of vineyard (Table 1). A management operation was applied for the land cover class WWHT (wheat) based on literature for crop management practices in this watershed (Lucas 2011).

SWAT was forced with climate datasets and simulated for the period 1997-2007 with extra six years of warming-up period to start the initial conditions of the model.

\subsection{Calibration and Validation}

A split-sample approach was applied to calibrate discharge, using part of the dataset for calibration (1997-2007) and an independent dataset for validation (1986-1996), without further parameter adjustment. The Gimonde hydrometric station (outlet 14) was used for daily calibration and validation. Rabal (outlet 6) was only used for monthly calibration and validation, since the station is highly influenced by the reservoir (Serra Serrada) and daily reservoir management is difficult to correctly implement in SWAT, limiting the reproducibility of daily discharge data.

SWAT calibration was done manually by adjusting some sensitive parameters against daily-observed discharge for the period of 1997-2007 (Table 3). The parameters changed to improve discharge simulation were: Alpha_BF (Baseflow alpha factor) initial value: 0.048, 


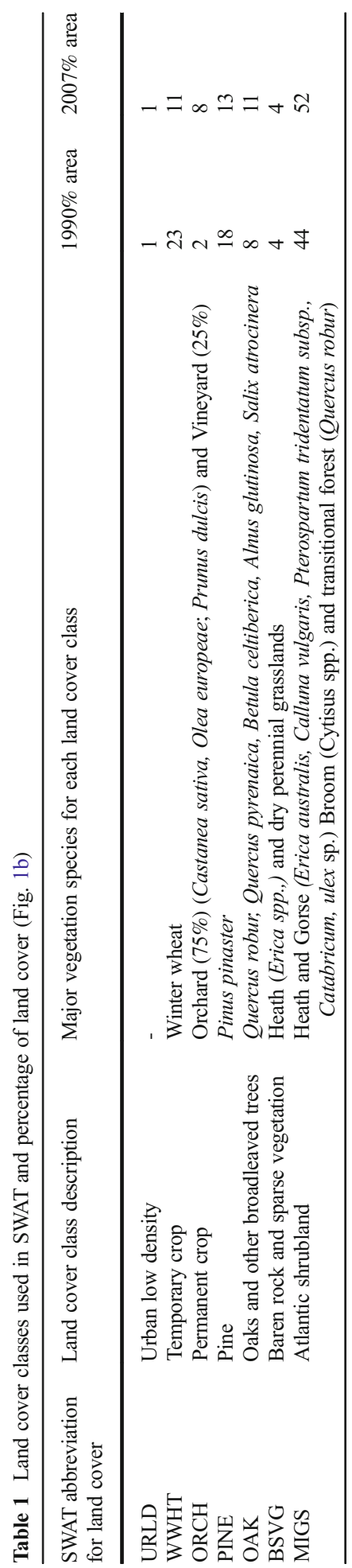




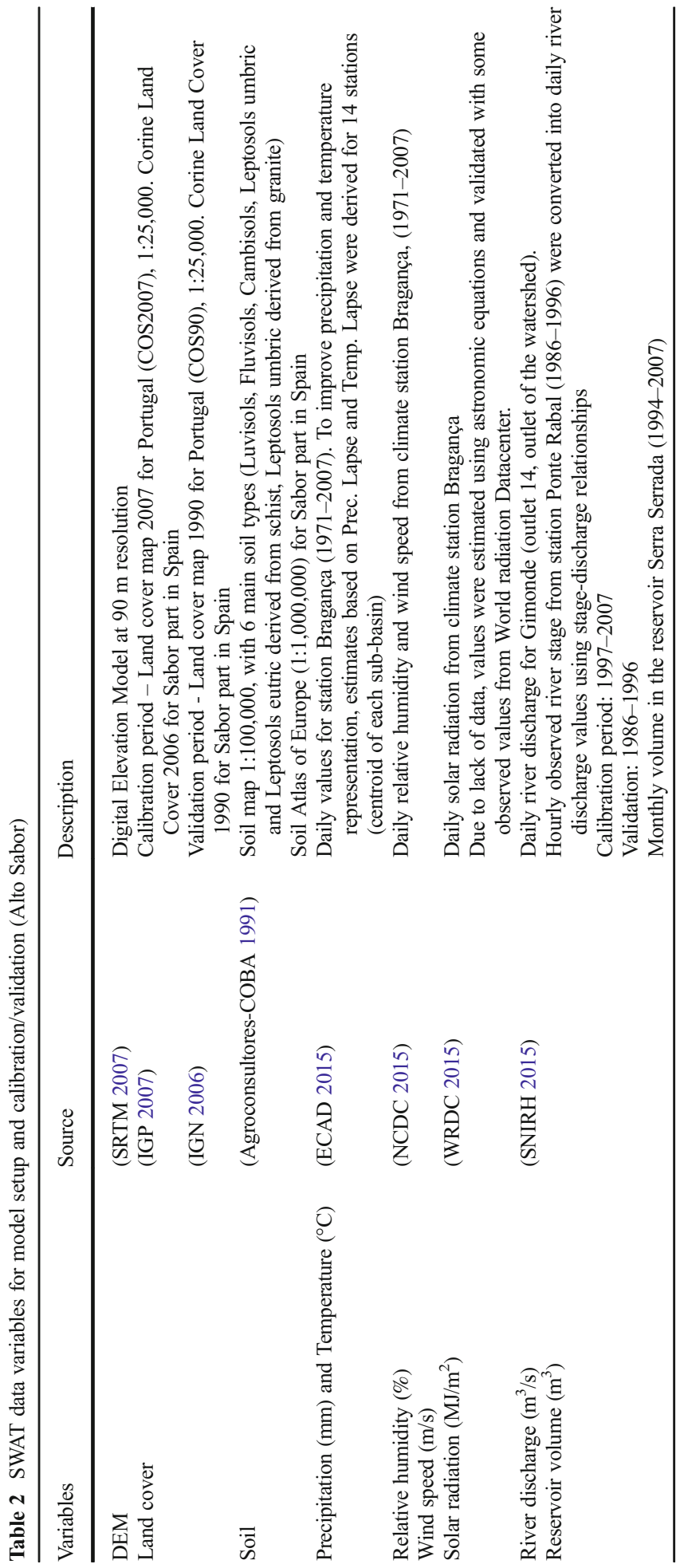


Table 3 Modified SWAT general parameters for Sabor watershed

\begin{tabular}{|c|c|c|c|}
\hline Parameters & Description & $\begin{array}{l}\text { Initial } \\
\text { value }\end{array}$ & Calibration value \\
\hline Alpha_BF & Baseflow alpha factor (days) & 0.048 & $\begin{array}{l}0.08 \text { (upstream outlet6) } \\
0.15 \text { (downstream outlet } 6 \text { ) }\end{array}$ \\
\hline RCHGR_DP & Deep aquifer percolation fraction & 0.05 & 0 \\
\hline GW_delay & Groundwater delay time (days) & 31 & 10 \\
\hline DEPIMP_BSN & Depth to impervious layer (mm) & 0 & 2000 \\
\hline USLE_P & Support practice factor & 1 & 0.5 (WWHT, ORCD) \\
\hline USLE $\mathrm{K}$ & Soil erodibility factor & 0.26 & 0.038 \\
\hline OV_N & Manning's roughness coefficient & $0.14 / 0.15$ & $\begin{array}{l}0.8 \text { (Oak, Pine, MIGS) } \\
0.17 \text { (WWHT)/ } 0.2 \text { (ORCD) }\end{array}$ \\
\hline RES_K & $\begin{array}{l}\text { Effective saturated hydraulic conductivity of the } \\
\text { reservoir bottom }(\mathrm{mm} / \mathrm{h})\end{array}$ & 0 & 2 \\
\hline WURESN & Average water removal from the reservoir $\left(10^{4} \mathrm{~m}^{3}\right)$ & 0 & $\begin{array}{l}0.8 \text { (Jul. to Sep.) } \\
0.5 \text { (Oct. and Jan. to May); } \\
0.3 \text { (Nov.); } 0.4 \text { (Dec.) }\end{array}$ \\
\hline
\end{tabular}

used value: 0.08 for the sub-basins upstream outlet 6 , and 0.15 for the sub-basins downstream outlet 6; RCHGR_DP (Deep aquifer percolation fraction) initial value: 0.05 , used value: 0 ; GW_delay (Groundwater delay time) initial value: 31, used value: 10; and DEPIMP_BSN (Depth to impervious layer) initial value: 0, used value: 2000. The USLE_K (Soil erodibility factor) was changed according to values mapped for Europe (Panagos et al. 2014). The OV_N (Manning's roughness coefficient) was updated with new values according to land cover (USDA 1986).

The monthly-observed volume of the Serra Serrada reservoir, which started functioning in 1989, was used to calibrate the reservoir volume. A continuous dataset of monthly-observed volumes $\left(\mathrm{m}^{3}\right)$ was available for 2001-2003 (Table 2). The parameters changed in the reservoir input table were based on the public hydrological information system (SNIRH 2015). Among other parameters, WURESN (Average water removal from the reservoir $10^{4} \mathrm{~m}^{3}$ ) and RES_K (Effective saturated hydraulic conductivity of the reservoir bottom $(\mathrm{mm} / \mathrm{h})$ ) were changed. RES_K was set as 2. WURESN was set monthly as 0.8 from July to September; 0.5 in October and from January to May; 0.3 in November and 0.4 in December (APA 2012).

Model performance was evaluated with statistics commonly used in hydrological modelling, namely the coefficient of determination $\left(\mathrm{r}^{2}\right)$, the percentage bias (PBIAS), and the NashSutcliffe-Efficiency (NSE). The corresponding equations and how they relate with model performance can be found in Moriasi et al. (2007).

\subsection{Future Climate Scenarios}

Future climate was considered by forcing SWAT model with daily conditions in precipitation, maximum and minimum temperature for the scenarios RCP 4.5 and 8.5 (Representative Concentration Pathways), from the IPCC AR5 (Fifth Intergovernmental Panel on Climate Change assessment report) (Lenderink et al. 2007; Hurkmans et al. 2010; Meinshausen et al. 2011) during two periods (2021-2040 and 2041-2060). RCP 4.5 is a medium stabilization scenario where total radiative forcing is stabilized at $4.5 \mathrm{~W} \mathrm{~m}^{-2}$ post year 2100 (approximately $650 \mathrm{ppm} \mathrm{CO}_{2}$-equivalent) with all countries undertaken emissions mitigation policies simultaneously and effectively (Thomson et al. 2011; Vuuren et al. 2011). RCP 8.5 is a rising 
scenario with total radiative forcing increasing at $8.5 \mathrm{~W} \mathrm{~m}^{-2}$ in 2100 (approximately $1370 \mathrm{ppm}$ $\mathrm{CO}_{2}$-equivalent).

The linear scaling approach applied for downscaling and bias-correction of climate data follows a previous study in Portugal (Carvalho-Santos et al. 2016). The following Global Circulation Models (GCMs) were used: CNRM-CM5 (Centre National de Recherches Meteorologiques, France), CSIRO-MK3.6 (Commonwealth Scientific and Industrial Research Organisation, Australia), MRI-CGCM3 (Meteorological Research Institute, Japan) and MPIESM-LR (Max Planck Institute for Meteorology, Germany). Precipitation and temperature data from the weather station of Bragança (1981-2000) was considered for the bias-correction of future climate. Three 20-year time windows were used to generate climate variables: 19812000 (baseline), 2021-2040 and 2041-2060 (scenario periods).

\subsection{Indicators for Reservoir Water Supply}

Bragança, located in the southern limits of Alto Sabor watershed, is the main city in the studyarea and where the majority of the population lives (23,186 inhabitants) (INE 2016). Water supply to the city and the surrounding municipality, which comprises the Alto Sabor and adjacent watersheds, has been based in Serra Serrada reservoir (water supply of $2.1 \mathrm{hm}^{3} \mathrm{yr}^{-1}$ ), a medium-sized reservoir built in 1989 (Fig. 1), and also in several small water sources, such as wells and springs spread through the west part of the watershed $\left(2.14 \mathrm{hm}^{3} \mathrm{yr}^{-1}\right)$. This system has shown persistent water supply problems, especially during dry summers due to a combination of lack of water supply and increasing demand from population, emigrants returning for summer holidays. In recent years, about $25 \%$ of total water requirements had to be supplied by external sources, including occasional emergency supply by fire departments. This is further complicated by the fact that the current water uptake from Serra Serrada is only guaranteed at 95\% and can fail in drought years. To address this issue, a new reservoir (Veiguinhas) was projected, which started to function in 2015 and works together with the existing reservoir. Small water sources will be phased out of the supply system. Both reservoirs will therefore be expected to supply $4.24 \mathrm{hm}^{3} \mathrm{yr}^{-1}$, with Serra Serrada now supplying $1.82 \mathrm{hm}^{3} \mathrm{yr}^{-1}$ and Veiguinhas supplying $2.42 \mathrm{hm}^{3} \mathrm{yr}^{-1}$ (APA 2012). The water supply capacity of these two reservoirs was designed with a $99 \%$ supply guarantee rate, but this was calculated without taking into account future climate conditions.

To evaluate water supply from the reservoir system, two scenarios were compared: the previous situation of a single reservoir (Serra Serrada) supplying $2.1 \mathrm{hm}^{3} \mathrm{yr}^{-1}$, ignoring the part of the system supplied by small water sources; and the situation starting in 2015, with two reservoirs (Serra Serrada + Veiguinhas) supplying $4.24 \mathrm{hm}^{3} \mathrm{yr}^{-1}$. SWAT was used to simulate the water volume in the reservoir under the previously described climate change simulations (four models and respective RCP 4.5 and RCP 8.5). The SWAT parameters were set as the calibration simulation, with the exception of WURESN for the water extractions in the reservoir that was changed according to the environmental impact assessment report of Veiguinhas reservoir (APA 2012). For the two-reservoir scenario, WURESN $\left(10^{4} \mathrm{~m}^{3}\right)$ was set as: Serra Serrada ( 0.47 from October to May; 0.55 from June to September); Veiguinhas ( 0.63 from October to May; 0.73 from June to September). To compare the reservoir scenarios, an indicator of service satisfaction vs. service reliability was calculated (Martin-Carrasco and Garrote 2007; Iglesias et al. 2011). For this, the simulated average of the actual monthly consumptions of each reservoir (i.e., consumption limited by the available water supply in the reservoir) was estimated and compared to the average water demand introduced in the 
reservoir file (WURESN). Service satisfaction is simply the ratio between actual consumption and water demand. Given the high inter-annual and seasonal variability of supply and demand, service reliability is the ratio of months where actual consumption is above an acceptable ratio of water demand. In this work, a supply above $90 \%$ of demand was considered acceptable, in line with the value of $85 \%$ proposed by Martin-Carrasco and Garrote (2007), but slightly higher to reflect the domestic supply nature of this system vs. the irrigation supply that the authors studied. Finally, service reliability is compared to service satisfaction, in the control period and in the future climate scenarios (including the four climate models). This comparison gives an idea of water stress under future climate conditions in both the single-reservoir and the two-reservoir systems.

\section{Results and Discussion}

\subsection{SWAT Model Performance}

The comparison between daily observed and simulated discharge in the calibration and validation periods indicated that SWAT was able to capture and reproduce the average flows and seasonal variations in the Alto Sabor watershed, except during major high flows or extreme conditions, as it was the case of the period between the end of 2000 and beginning of 2001 (Fig. 2). Concerning model performance (Table 4), in Gimonde predictions for calibration can only be considered satisfactory, because of the strongly negative PBIAS being
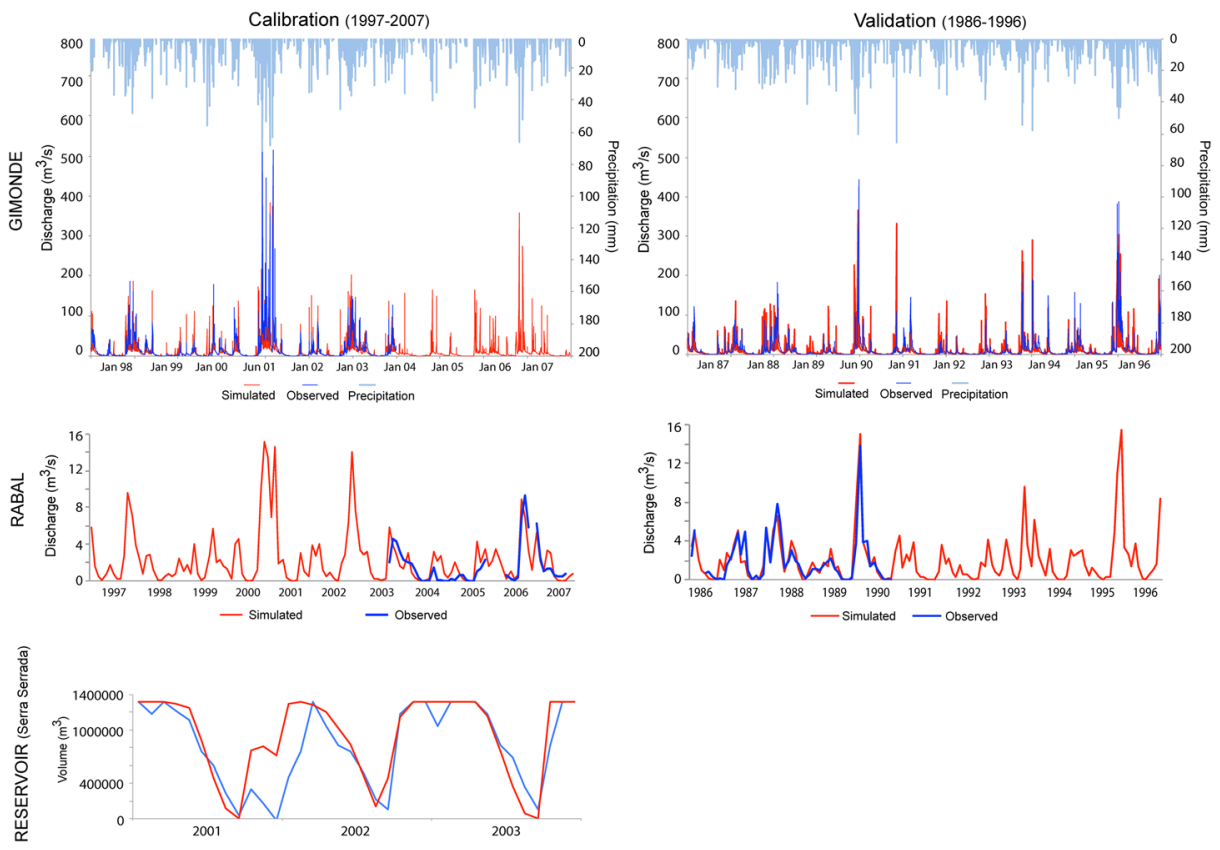

observed simulated

Fig. 2 Observed and simulated discharge (daily for Gimonde and monthly for Rabal) for calibration and validation period, and monthly reservoir volume, after parameter calibration (Table 3). Performance statistics are presented in Table 4 
Table 4 Calibration and validation goodness-of-fit statistics for discharge in SWAT model in Alto Sabor watershed

\begin{tabular}{|c|c|c|c|c|c|c|}
\hline & & \multicolumn{2}{|c|}{$\begin{array}{l}\text { Discharge calibration } \\
(1997-2007)\end{array}$} & \multicolumn{2}{|c|}{$\begin{array}{l}\text { Discharge validation } \\
(1986-96)\end{array}$} & \multirow{2}{*}{$\begin{array}{l}\text { Reservoir calibration } \\
\text { (2001-2003) } \\
\text { Serra Serrada }\end{array}$} \\
\hline & & Gimonde & Rabal & Gimonde & Rabal & \\
\hline \multirow[t]{2}{*}{$\mathrm{R}^{2}$} & Monthly & 0.89 & 0.63 & 0.85 & 0.85 & 0.68 \\
\hline & Daily & 0.56 & - & 0.63 & - & - \\
\hline \multirow[t]{2}{*}{ PBIAS (\%) } & Monthly & -21 & 9 & -19 & 8 & 12 \\
\hline & Daily & -21 & - & -19 & - & - \\
\hline \multirow{2}{*}{ NSE } & Monthly & 0.77 & 0.57 & 0.78 & 0.83 & 0.65 \\
\hline & Daily & 0.56 & - & 0.62 & - & - \\
\hline
\end{tabular}

under $-15 \%$ (Moriasi et al. 2007). The same applies for validation performance statistics (1984-1989). Satisfactory results for calibration and good results for validation were obtained for Rabal, with a slightly higher but still very good PBIAS, under 10\% (Moriasi et al. 2007). The observed discharge dataset in Rabal was incomplete, with a major data gap between the years 1991 and 2003. Possible reasons for the difference between both stations can be the weak representation of precipitation in the watershed, especially as a function of the topographic gradient, and the lower reliability of observed discharge data during peak flows.

The calibration of the volumes of the reservoir Serra Serrada can be considered good (Moriasi et al. 2007). It was only possible to calibrate against three complete years of reservoir volumes, but these years are representative of different hydrological conditions, namely an unusually wet year (2001) and a dry year (2003). It can therefore be concluded that SWAT was able to correctly represent both available water in the upper reaches of the Sabor and water storage in mountain reservoirs.

\subsection{Future Climate in Alto Sabor Watershed: Model and Scenario Variability}

In the future, a general increase of temperatures and a decrease in precipitation is expected in the Alto Sabor watershed (Fig. 3a). The temperatures will increase up to $6{ }^{\circ} \mathrm{C}$ in summer under RCP 8.5. The change in the precipitation however, is more uncertain due to seasonal variations (Fig. 3a) and the variability given by the four different climate models used (Fig. 3b). In seasonal terms it is expected
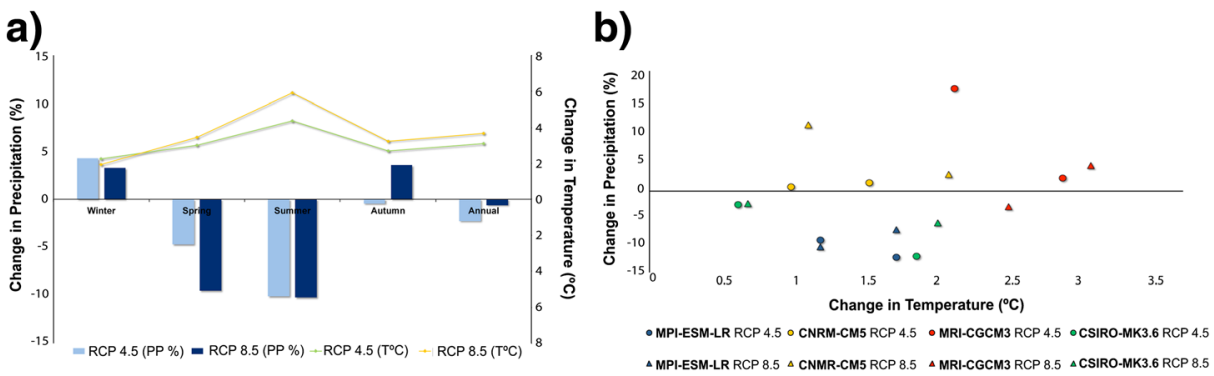

Fig. 3 Future climate, models and scenarios: a Seasonal variation in the average temperature $\left({ }^{\circ} \mathrm{C}\right)$ and precipitation (\%), for the scenarios RCP 4.5 and 8.5, compared to 1981-2000. b Variability of the four different climate models (CNRM-CM5; CSIRO-MK3.6; MPI-ESM-LR; MRI-CGCM3) related to changes in precipitation $(\%)$ and temperature $\left({ }^{\circ} \mathrm{C}\right)$ when compared to 1981-2000, and under different climate scenarios (circles refer to RCP 4.5 and triangles to RCP 8.5 ) 
more precipitation in winter and much less in spring and summer. These projected increases in temperature and changes in the intensity and pattern of precipitation are consistent with previous studies in Portugal (Cunha et al. 2005; Nunes et al. 2008; Carvalho-Santos et al. 2016) and in Galicia, northwest Spain (Álvarez et al. 2011). When comparing climate scenarios, RCP 8.5 has a higher change in temperature and a marked difference in seasonal precipitation when compared to RCP 4.5 (Fig. 3a). This pattern in scenarios was also shown in a study with high-resolution Regional Climate Models (RCM) in Europe, Euro-Cordex (Jacob et al. 2013).

If a consensus was observed between different climate models regarding an increase in temperature (annual change between $+0.5{ }^{\circ} \mathrm{C}$ and $+3{ }^{\circ} \mathrm{C}$ ), precipitation in turn shows high variability in the pattern of change according to the selected model (results ranging between $-15 \%$ and $+7 \%$ ). The CNRM-CM5 and MRI models project an increase in annual precipitation, whereas CSIRO-MK3.6 and MPI-ESM-LR project a decrease (Fig. 3b). Internal model variability for precipitation is recognized as an important source of uncertainty in climate projections (Northrop and Chandler 2014). A similar situation was found in a recent study of reservoir resilience under climate change in Italy, where changes in precipitation ranged from $-170 \mathrm{~mm}$ to $+31 \mathrm{~mm}$ (Mereu et al. 2016). This variability given by the different models may also be due to the location of the Alto Sabor watershed, namely in the transition zone between Mediterranean and Atlantic types of climate (Metzger et al. 2005).

\subsection{The Reservoirs and Water Supply under Climate Change}

In general, our results indicate that there will be less water in the reservoirs in the future, especially in 2041-2060 (Fig. 4). This was more visible for the new reservoir Veiguinhas. Taking the variability of the modelling projections into account, RCP 4.5 forecasts more water in the reservoirs in 2021-2040 and a drastic reduction in 2041-2060. Another general trend is a reduction in the summer reservoir volumes and an increase in the winter volumes, more visible under RCP 8.5.

Res. 1 - Serra Serrada
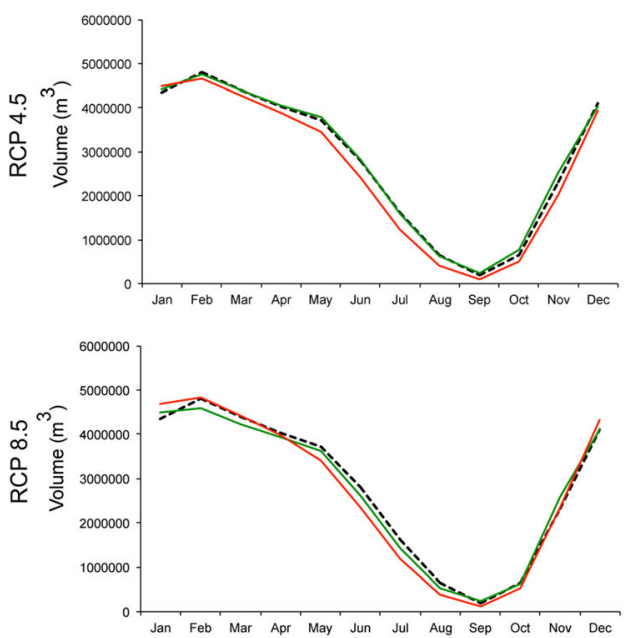

Res. 2 - Veiguinhas
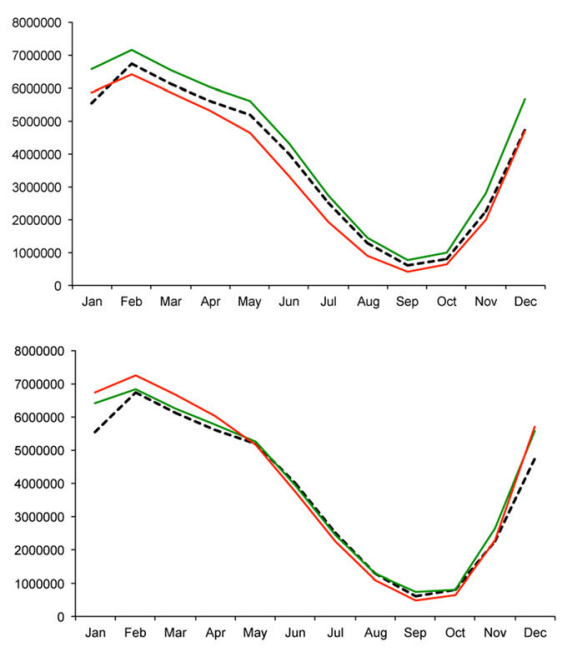

--- control $-2021-2040-2041-2060$

Fig. 4 Climate change impacts on seasonal reservoir volume $\left(10^{4} \mathrm{~m}^{3}\right)$, for the periods $2021-2040$ and $2041-$ 2060 compared to control (1981-2000), RCP 4.5 and 8.5 
In terms of reliability of the system (both with one and two reservoirs) to supply water under future climate conditions (Fig. 5), one major result is that the two-reservoir system would have solved the problem of water supply in the last decades (1981-2000), with service satisfaction above $90 \%$. In turn, the single-reservoir system always shows water stress, becoming worst under future climate, especially in 2041-2060. The two-reservoir system should supply water with satisfaction and reliability above $90 \%$ in the period 2021-2040, although under scenario RCP 8.5 the situation is closer to the $90 \%$ threshold. Failure of reliability in water supply occurs mostly during summer months (Fig. 4). After 2040, service reliability decreases to values around $80 \%$, especially under the RCP 4.5 scenario (Fig. 5).

When considering the result of specific climate models, projections for service reliability can still be more negative (see grey dots in Fig. 5). Here, the different precipitation inputs from the different climate models (Fig. 3b) enlarge the window of uncertainty. Models predicting more precipitation show an increase in the reliability of the system, whereas models predicting less precipitation decrease the levels of service reliability.

It should be highlighted that this study considers changes in water supply in the future under climate change, whereas water demand was kept constant throughout the simulation period. Since this is a small watershed located in inland Portugal, a significant increase in urban water demand is not foreseeable. In fact, demand for water is even likely to decrease in the future due to water efficiency measures and education of urban population (Jacinto et al. 2013).

\subsection{Implications for Watershed and Reservoir Management}

To our knowledge, this study is a first contribution for climate impact assessment of a local reservoir system for water supply. These studies are important to create adaptive capacity to cope with climate change (Iglesias et al. 2011). The approach considers not only water availability, but also demand for domestic use. The two-reservoir system is effectively prepared to supply water with high reliability until 2040. Still, during the dry years the system may not respond effectively during the critical summer months. One option to cope with this problem is to create an alert system for a drought management plan, which may include the definition of a demand reduction (Rossi et al. 2012).

RCP 4.5

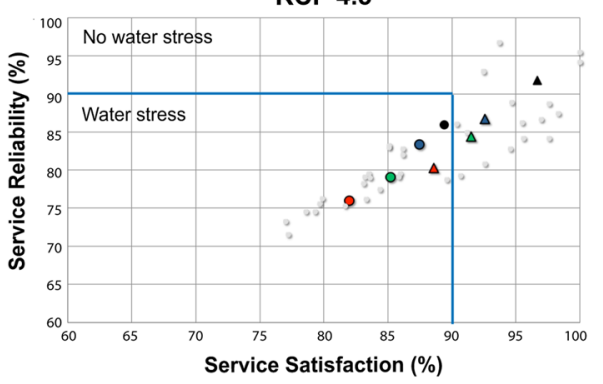

RCP 8.5

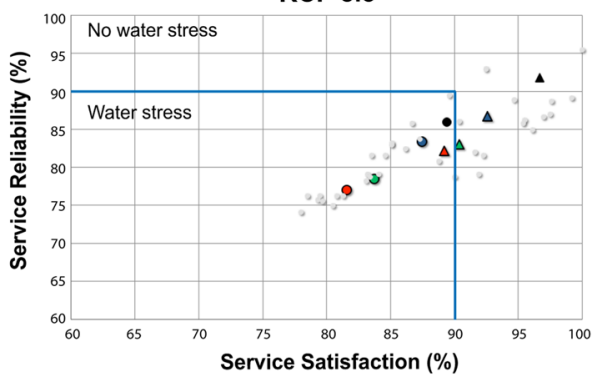

Bragança-1 rsv $\Delta$ Bragança-2 rsv 0 1981-2000-1 rsv $\Delta$ 1981-2000-2 rsv 0 2021-2040-1 rsv

$\boldsymbol{\Delta}$ 2021-2040 - 2 rsv 0 2041-2060 - 1 rsv $\boldsymbol{\Delta}$ 2041-2060 - 2 rsv models variability

Fig. 5 Reservoir service satisfaction vs. service reliability (ensemble SWAT climate models simulations, for RCP 4.5 and RCP 8.5 scenarios, period 2021-2040 (green) and 2041-2060 (red)). Circles refer to single-reservoir system, and triangles to two-reservoir system. Control period from climate models in blue (1981-2000), "Bragança" refers to SWAT simulation using observed data from climate station Bragança (1981-2000). Grey dots show the simulations driven by each individual climate model. Supply above $90 \%$ demand is considered acceptable 
When reservoirs become inadequate, either there is an increase in reservoir volume maintaining the same target demand, or a reduction in demand while maintaining the same reservoir volume (Liuzzo et al. 2014). Considering that the two-reservoir system is located in a small drainage area in the top of the mountain (a preferable place for maintaining water quality), increasing reservoir volume is not an option. One suggestion could be a possible reservoir downstream to increase the drainage area. However, the consequences for habitat requirements for aquatic species downstream the reservoirs should be considered, as it was shown in a study in a similar watershed in northern Portugal (Santos et al. 2015). Thus, land management for water regulation at the watershed level would be a preferred solution, more compatible with nature conservation regulations and with potential wider benefits for biodiversity and for other ecosystem services (Carvalho-Santos et al. 2016).

Regarding the consequences of seasonal changes for general water resources, more water in the system during autumn and winter can bring benefits for agriculture and irrigation, but on the other hand it may bring risk of floods, especially if precipitation occurs in strong and short episodes. This was shown in a medium watershed in northwest Portugal, in which under scenarios of climate change, the increase of precipitation in autumn may increase the risk of floods (Carvalho-Santos et al. 2016). Attention should be paid to the lower streamflow and reservoir volumes during spring and summer under future climate, which may cause water shortages, problems in water quality and consequences for aquatic biodiversity (Hughes et al. 2012).

\section{Conclusions}

In the future, a general increase of temperatures is expected in the Alto Sabor watershed, but the change in precipitation is more uncertain, with differences according to the selected climate model. However, seasonal changes would be more significant, with more precipitation in winter and much less in spring and summer, with impacts on the water resources.

In the future, the volume of water stored in the reservoirs of Alto Sabor watershed will decrease, especially during spring and summer. The existence of two reservoirs will likely solve the water supply problems under current climate conditions, but in the future the reliability of this solution will decrease, especially under scenario RCP 8.5 for 2041-2060. Here, the variability given by the different climate models simulated in SWAT brings some uncertainty with respect to the precipitation inputs. This variability has to be taken into account in the future, considering the general tendencies described in this study. One general concern is the limitations on water supply in very dry summer months, which is predicted as a problem independently of the climate model used.

The main conclusion of this study is that the solution projected for water supply in this region, calculated taking only present-day climate into account, will probably be inefficient for water supply management under future climate. Taking climate change into account would have avoided the need for further investment in the future, and calls for an integrative strategy that favours water regulation ecosystem services in the wider landscape.

Acknowledgements This work was funded by FEDER funds through the Operational Programme for Competitiveness Factors - COMPETE and by National Funds through FCT - Foundation for Science and Technology under the project PTDC/AAG-MAA/4539/2012 / FCOMP-01-0124-FEDER-027863 (IND_CHANGE). J.P. Nunes was financially supported by FCT (Portuguese Science Foundation), and the European Social Fund through post-doctoral grant (SFRH/BPD/87571/2012). A.T. Monteiro is supported by FEDER funds through the Operational Programme for Competitiveness Factors - COMPETE and by National Funds through FCT Foundation for Science and Technology under the UID/BIA/50027/2013 and POCI-01-0145-FEDER-006821. The authors would like to thank the Municipality of Bragança for the datasets on water inflows. 


\section{References}

Agroconsultores-COBA (1991) Carta de Solos da Região de Trás-os-Montes e Alto Douro (1:100 000). (Soil map from the region Trás-os-Montes e Alto Douro), Universidade de Trás-os-Montes e Alto Douro, Bragança [in Portuguese]

APA (2012) Reforço de Abastecimento de Água a Bragança (water supply strengthening plan for Bragança). APA - Agencia Portuguesa do Ambiente (Portuguese Environmental Agency)

Arnold JG, Srinivasan R, Muttiah RS, Williams JR (1998) Large area hydrologic modeling and assessment part I: model development. J Am Water Resour Assoc 34:73-89

Álvarez V, Taboada JJ, Lorenzo MN (2011) Cambio climático en Galicia en el siglo XXI: Tendencias y variabilidad en temperaturas y precipitaciones (Climate Change in Galicia by the XXI century: tendencies and variability in temperatures and precipitation). Revista Avances en Ciencias de la Terra (ACT) 2:65-85

Bangash RF, Passuello A, Sanchez-Canales M et al (2013) Ecosystem services in Mediterranean river basin: climate change impact on water provisioning and erosion control. Sci Total Environ 458-460:246-255

Carvalho-Santos C, Nunes JP, Monteiro AT et al (2016) Assessing the effects of land cover and future climate conditions on the provision of hydrological services in a medium-sized watershed of Portugal. Hydrol Process 30:720-738

Castro J, de Figueiredo T, Fonseca F et al (2010) Montesinho Natural Park: general description and natural values. In: Evelpidou N, de Figueiredo T, Mauro F, Tecim V (eds) Natural heritage from east to west. Springer - Verlag, Heidelberg, pp 119-132

Cunha LV, Oliveira R, Nunes V (2002) WaterResources. In: Santos FD, Forbes K, Moita R (eds) Climate change in Portugal scenarios, impacts and adaptation measures - SIAM project. Gradiva Publishers, Lisbon, pp 1-38

Cunha LV, Oliveira RP, Nascimento J, Ribeiro L (2005) Impacts of climate change on water resources: a casestudy for Portugal. The Fourth Inter-Celtic Colloquim on Hydrology and Management of Water Resources International Association of Hydrological Sciences, July 11-14, Guimarães, Portugal

ECAD (2015) European climate assessment \& dataset. Royal Netherlands Meteorological Institute (KNMI). Available online at http://eca.knmi.nl/. Accessed Jan 2015

EEA (2003) Water exploitation index. European Environment Agency

Falkenmark M, Rockstrom J (2004) Balancing water for humans and nature. Earthscan, London

Feng S, Hu Q, Huang W et al (2014) Projected climate regime shift under future global warming from multimodel, multi-scenario CMIP5 simulations. Glob Planet Chang 112:41-52

Galván L, Olías M, Izquierdo T, Cerón JC (2014) Rainfall estimation in SWAT: an alternative method to simulate orographic precipitation. J Hydrol 509:257-265

Gassman PW, Reyes MR, Green CH, Arnold JG (2007) The soil and water assessment tool: historical development, applications, and future research directions. Trans ASABE 50:1211-1250

Giorgi F, Lionello P (2008) Climate change projections for the Mediterranean region. Glob Planet Chang 63:90104

Hurkmans R, Terink W, Uijlenhoet R et al (2010) Changes in streamflow dynamics in the rhine basin under three high-resolution regional climate scenarios. J Climate 23:679-699

Hughes SJ, Cabecinha E, Andrade dos Santos JC et al (2012) A predictive modelling tool for assessing climate, land use and hydrological change on reservoir physicochemical and biological properties. Area 44:432-442

INE (2016) Instituto Nacional de Estatística (Portuguese National Statistics). Retrieved from: www.ine.pt. Accessed Dec 2016

Iglesias A, Garrote L, Diz A et al (2011) Re-thinking water policy priorities in the Mediterranean region in view of climate change. Environ Sci Pol 14:744-757

IGN, Instituto Geográfico Nacional de España (Spanish Geographic Institute) (2006) Retrieved from: www.ign. es. Accessed Jan 2015

IGP (2007) Carta de Ocupação e Uso do Solo 1990 e 2007 (Land Cover and Use map 1990 and 2007). IGP Instituto Geográfico Português (Portuguese Geographical Institute). Accessed Jan 2015. [in Portuguese]

Jacinto R, Cruz MJ, Santos FD (2013) Development of water use scenarios as a tool for adaptation to climate change. Drink Water Eng Sci 6:61-68

Jacob D, Petersen J, Eggert B et al (2013) EURO-CORDEX: new high-resolution climate change projections for European impact research. Reg Environ Chang 14:563-578

Kundzewicz ZW, Mata LJ, Arnell NW et al (2008) The implications of projected climate change for freshwater resources and their management. Hydrol Sci J 53:3-10

Lenderink G, Buishand A, van Deursen W (2007) Estimates of future discharges of the river rhine using two scenario methodologies: direct versus delta approach. Hydrol Earth Syst Sci 11:1143-1159

Liuzzo L, Noto LV, Arnone E et al (2014) Modifications in water resources availability under climate changes: a case study in a Sicilian Basin. Water Resour Manag 29:1117-1135 
Lorenzo-Lacruz J, Vicente-Serrano SM, González-Hidalgo JC et al (2013) Hydrological drought response to meteorological drought in the Iberian Peninsula. Clim Res 58:117-131

López-Moreno JI, Zabalza J, Vicente-Serrano SM et al (2014) Impact of climate and land use change on water availability and reservoir management: scenarios in the upper Aragón River, Spanish Pyrenees. Sci Total Environ 493:1222-1231

Lucas MJ (2011) Recenseamento Agrícola 2009 - Práticas agrícolas (Agricultural Inventory 2009 - Management in Agriculture. INE - Instituto Nacional de Estatistica (Statistical National Institute)

Martin-Carrasco F, Garrote L (2007) Drought-induced water scarcity in water resources systems. In: Vasiliev OF, van Gelder PHAJM, Plate EJ, Bolgov MV (eds) Extreme hydrological events: new concepts for security. NATO Science Series, pp 301-311

Meinshausen M, Smith SJ, Calvin K et al (2011) The RCP greenhouse gas concentrations and their extensions from 1765 to 2300. Clim Chang 109:213-241

Mereu S, Sušnik J, Trabucco A et al (2016) Operational resilience of reservoirs to climate change, agricultural demand, and tourism: a case study from Sardinia. Sci Total Environ 543:1028-1038

Mesquita S, Sousa AJ (2009) Bioclimatic mapping using geostatistical approaches: application to mainland Portugal. Int J Climatol 29:2156-2170

Metzger MJ, Bunce RGH, Jongman RHG et al (2005) A climatic stratification of the environment of Europe. Glob Ecol Biogeogr 14:549-563

Molina-Navarro E, Trolle D, Martínez-Pérez S et al (2014) Hydrological and water quality impact assessment of a Mediterranean limno-reservoir under climate change and land use management scenarios. J Hydrol 509: $354-366$

Moriasi DN, Arnold JG, Van Liew MW et al (2007) Model evaluation guidelines for systematic quantification of accuracy in watershed simulations. Trans ASABE 50:885-900

Mourato S, Moreira M, Corte-Real J (2015) Water resources impact assessment under climate change scenarios in Mediterranean watersheds. Water Resour Manag 29:2377-2391

NCDC (2015) National climatic data center. National Oceanic and Atmospheric Administration. U. S. Department of Commerce. Available online at http://www.ncdc.noaa.gov/. Accessed Jan 2015

Neitsch SL, Arnold JG, Kiriny JR, Williams JR (2011) Soil \& water assessment tool. Theoretical Documentation. Version 2009. Texas A\&M University System, College Station

Northrop PJ, Chandler RE (2014) Quantifying sources of uncertainty in projections of future climate. J Clim 27: 8793-8808

Nunes JP, Seixas J, Pacheco NR (2008) Vulnerability of water resources, vegetation productivity and soil erosion to climate change in Mediterranean watersheds. Hydrol Process 22:3115-3134

Panagos P, Meusburger K, Ballabio C et al (2014) Soil erodibility in Europe: a high-resolution dataset based on LUCAS. Sci Total Environ 479-480:189-200

Rossi G, Caporali E, Garrote L (2012) Definition of risk indicators for reservoirs management optimization. Water Resour Manag 26(4):981-996

Samani Z (2000) Estimating solar radiation and evapotranspiration using minimum climatological data (Hargreaves-Samani equation). J Irrig Drain Eng 126(4):265-277

Santos RMB, Sanches Fernandes LF, Varandas SGP et al (2015) Impacts of climate change and land-use scenarios on Margaritifera margaritifera, an environmental indicator and endangered species. Sci Total Environ 511:477-488

Shen Y, Oki T, Utsumi N et al (2010) Projection of future world water resources under SRES scenarios: water withdrawal. Hydrol Sci J 53:11-33

SNIRH (2015) Sistema Nacional de Informação de Recursos Hídricos (National Hydrological Resources Information System). Portuguese Water Institute (INAG), Lisboa. Retrieved from: snirh.pt. Accessed Jan 2015. [in Portuguese]

SRTM (2007) Digital elevation database 90m, v4-1, CGIARCSI - consortium for spatial information available online at http://www.cgiar-csi.org/data/srtm-90m-digital-elevation-database-v4-1. Accessed Jan 2015

Thomson AM, Calvin KV, Smith SJ et al (2011) RCP4.5: a pathway for stabilization of radiative forcing by 2100. Clim Chang 109:77-94

Tsakiris G (2015) The status of the European waters in 2015: a review. Environ Process 2:543-557

USDA (1986) Urban hydrology for small watersheds. Natural Resources Conservation Service, Conservation Engineering Division, United States Department of Agriculture. Technical release 55

Vuuren DP, Edmonds J, Kainuma M et al (2011) The representative concentration pathways: an overview. Clim Chang 109:5-31

Winchell M, Srinivasan R, Di Luzio M, Arnold JG (2010) ArcSWAT Interface for SWAT2009

WRDC (2015) World radiation data center. Available online at http://wrdc-mgo.nrel.gov/. Accessed Jan 2015 